\title{
Reinforcing effect of hardwoods on the moment resistance performance of traditional Japanese "nuki"-column joints
}

\author{
Hiroto Suesada ${ }^{*} \mathbb{( D}$, Kohta Miyamoto ${ }^{1}$, Tatsuya Shibusawa ${ }^{1}$, Kenji Aoki ${ }^{2}$ and Masahiro Inayama ${ }^{2}$
}

\begin{abstract}
In traditional Japanese timber structures, nuki-column joints are used as seismic elements. However, the elastic stiffness of their moment resistance performance is rather small. In this research, hardwoods were used for nuki in three ways to improve the performance of the joints. Moment resistance tests of the joints were conducted to evaluate their structural performance and clarify the differences depending on the wood species, the nuki cross sections, and reinforcing effects of hardwoods discussed. In some specifications, it was shown that using hardwoods for nuki improved the structural performance of the joints. A significant effect was observed on some characteristic values of the joints.
\end{abstract}

Keywords: Traditional timber joint, Hardwoods, Moment-resisting joint, Reinforcement

\section{Introduction}

In Japan, the domestic hardwood supply was about 218 million $\mathrm{m}^{3}$ in 2018 [1], and the $6.52 \%$ of its portion was used for material. The remaining portion was almost used as wood chips for paper and board products. There are hardwood species that exhibit an excellent mechanical performance compared to softwood [2]. Therefore, using these hardwoods as structural members in wooden constructions will be beneficial, although softwood is more commonly used currently. One of the reasons for this is that no databases containing characteristic values for hardwood have been established. The implementation of hardwoods as structural members can lead to the effective use of hardwood resources.

In Japan, nuki-column joints are one of the elements that resist external forces in traditional architectures. Nuki-column joints comprise a column, wedges, and horizontal members having a small cross-sectional area called nuki. The elastic rotational stiffness and yield moment of nuki-column joints are known to be small, whereas their deformation capacity is very large because

\footnotetext{
*Correspondence: hsuesada@ffpri.affrc.go.jp

${ }^{1}$ Forestry and Forest Products Research Institute, 1 Matsunosato, Tsukuba, lbaraki 305-8687, Japan

Full list of author information is available at the end of the article
}

most of the deformation of the joints is due to partial compressive deformations perpendicular to the grain of nuki. The characteristic values of nuki-column joints can improve by suppressing this deformation. In partial compressive deformations of wood, compressive strain is locally generated at near the surface loading area and end of this area of the wood. Inside the wood, the local compressive strain is reduced and the strain is made uniform. Therefore, the partial compressive deformation can be reduced by disposing a material having excellent compression performance near the surface loading area [3].

Thus, we consider utilizing hardwoods in the joints to solve these problems. In Japan, wooden fastenings such as kusabi and wooden dowel are used in some traditional Japanese timber connections and are usually made from hardwood. Many studies about these connections were conducted, such by Kitamori [4] and Fujita [5]. These fastenings were used to connect with elements of the connections and appeared complex behavior when the connection was loaded because the fastenings were independent materials. In this study, hardwood elements were used to reinforce nuki-column connections and appeared different behavior from the fastening because the elements were bonded with nuki. Some of the studies about improving the performance of connections using hardwoods are follows. Nakajima indicated that the 
performance of tensile bolt joint on column and beam connections improved using acacia boards in order to prevent the compressive deformation perpendicular to the grain of columns from metal washers [6]. Gotoh indicates that the performance of penetrating nuki-column connections improved using hardwoods as yatoi [7]. Wanninger used hardwood on a part of the posttensioned timber connection in order to protect deformation perpendicular to the grain of the column and beam [8]. The authors had experimented nuki-column joints using hardwood as nuki and demonstrated positive effects of using hardwood [9].

In this study, we tried to improve the performance of nuki-column joints by hardwood with a small cross section and to substantiate its positive effects on characteristic values of the joints. This is because that utilizing hardwoods with a small cross section is recommended because obtaining hardwoods with a large cross section is difficult in Japan. Thus, in this study, moment resistance tests were performed on nuki-column joints using hardwood with a small cross section as reinforcements and the results of the tests were compared to the ones of unreinforced nuki-column joints. In this report, the results of previous study [9] were also shown for comparison with the results of this study.

If this study is able to substantiate the positive effect of reinforcing nuki-column joints with hardwoods, we may expand the use of hardwoods as structural members and support the design of constructions in the traditional method. Additionally, the same procedure for reinforcing nuki-column joints with hardwoods may be applied to other joints because nuki-column joints are extremely simple.

\section{Specimens and methods}

\section{Specimens}

In this study, the specimens comprised a column and a nuki without wedges. The column had the 90 -mm-deep mortise of the same cross-sectional dimensions as nuki. The cross-sectional dimensions of the column were $120 \mathrm{~mm}$ by $120 \mathrm{~mm}$, and the length was $900 \mathrm{~mm}$. The species of the column is sugi (Cryptomeria japonica). There were three types of nuki, namely N, Rs, and Rl. N type indicates a nuki made of a single piece. For the Rs and $\mathrm{Rl}$ types, the first character, $\mathrm{R}$, indicates that the nuki is made of sugi with reinforcements.

The Rs-type specimen has short reinforcements; they are $120 \mathrm{~mm}$ long. The Rl-type specimen has long reinforcements; they are $445 \mathrm{~mm}$ long. The length of all the nuki types was $445 \mathrm{~mm}$. The heights of the $\mathrm{N}$-type nuki, shown as $b_{\mathrm{n}}$ in Fig. 1, were 60, 75, and $90 \mathrm{~mm}$, and the widths, shown as $w_{\mathrm{n}}$ in Fig. 1 , were 30 and $45 \mathrm{~mm}$. The heights and widths of both Rs- and Rl-type nuki were $90 \mathrm{~mm}$ and $30 \mathrm{~mm}$, respectively. In this study, the species

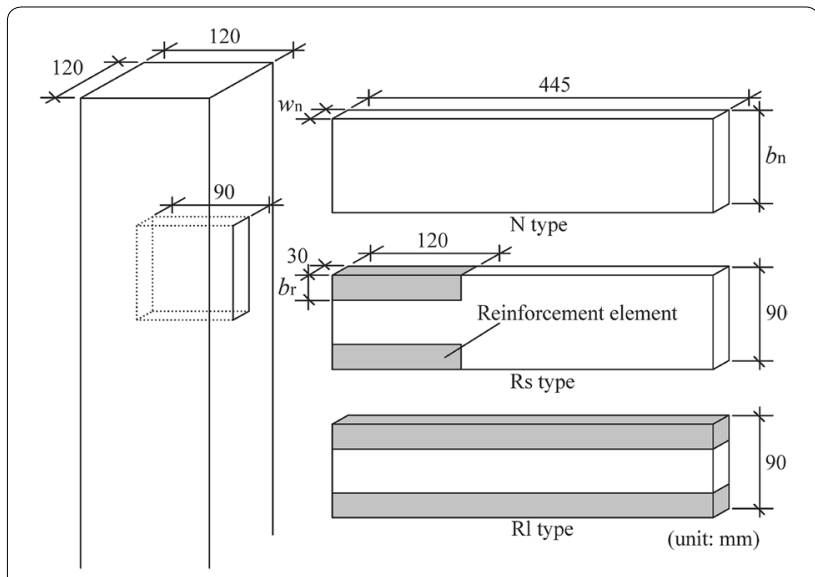

Fig. 1 Types and dimensions of specimen

of N-type nuki were sugi. The moment resistance tests of N-type specimens were conducted in addition to the previous tests [9] in order to compare to R-type specimens as the no reinforcement nuki. Rs- and Rl-type nuki were made from sugi and reinforced with two hardwood species (kuri and shirakashi) and one softwood species (hinoki) for comparison between hardwood and softwood. The width of the Rs- and Rl-type reinforcements was $30 \mathrm{~mm}$, and the heights were 12,18 , and $24 \mathrm{~mm}$. The number of $\mathrm{N}$-type specimens in each specification was six, and that of the Rs- and Rl-type specimens was three.

\section{Reinforcement nuki element}

As the raw material of the reinforcements, 18 lumbers with cross-sectional dimensions of $30 \mathrm{~mm}$ by $30 \mathrm{~mm}$ and a length of $1000 \mathrm{~mm}$ were prepared for each wood species. For each wood species, the reinforcements were allocated such that the density was not biased for any of the specimens to reduce variations in the wood properties. In addition, the combination of lumbers from which reinforcements were made was the same between the Rs and Rl types. The density of the reinforcements was the one of the lumbers from which the reinforcements were made. The shape of the sugi piece of nuki of Rs-type was cut out the shape of reinforcing elements. The specimens were manually glued, cramped between plywood and cured for about 2 weeks. Further, they were shaped to the target size using a manual planer machine. The adhesive that bonded the reinforcing elements to nuki was a polyurethane resin (UR-20, Oshika Corporation, Japan).

\section{Methods}

Figure 2 shows details of the loading apparatus. The tip of the nuki and the bottom of a column were connected to the load-jig and the foundation-jig, respectively, using an M20 bolt for pin connection. The load-jig had two M20 


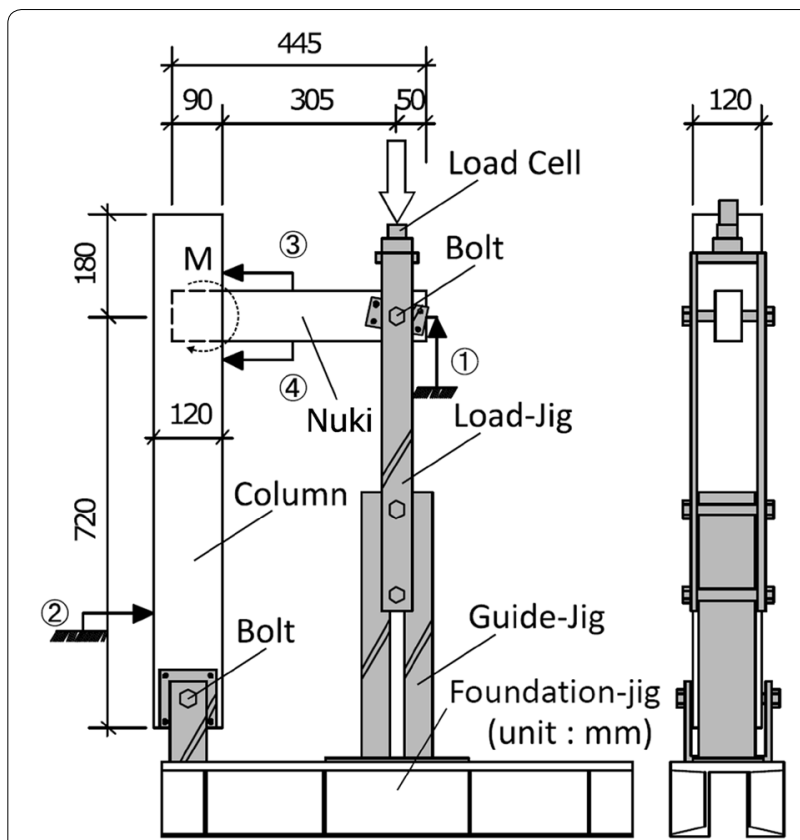

Fig. 2 Loading setup bolts mounted side by side in the vertical direction. The bolts passed through the gap between the two steel members of the guide-jig $(22 \mathrm{~mm})$ and the tip of nuki moved only in the vertical direction. The vertical load applied to the tip of the nuki generated moment at the nuki-column joint. Static monotonic loading tests were performed until the rotation angle of the specimen reached 1/5 rad or until the load decreased to $80 \%$ of the maximum load. The rotation angle of a specimen is the sum of three angles: the deformation angle of the nuki-column joint, the rotation angle of a column, and the bending deformation angles of the members of a specimen. This angle was calculated using the measured values of the displacement transducers (1) and (2) in Fig. 2) on the tip of nuki and beside the column. The loading rate was $5 \mathrm{~mm} / \mathrm{min}$. The deformation angle of the joint was calculated from the horizontal displacement that was recorded by the displacement transducers (3) and (4) in Fig. 2) above and below nuki. The moment generated at the joint was calculated by multiplying the load by the length of the moment arm, $305 \mathrm{~mm}$ (i.e., the distance from the application point of the load to the surface of the column).

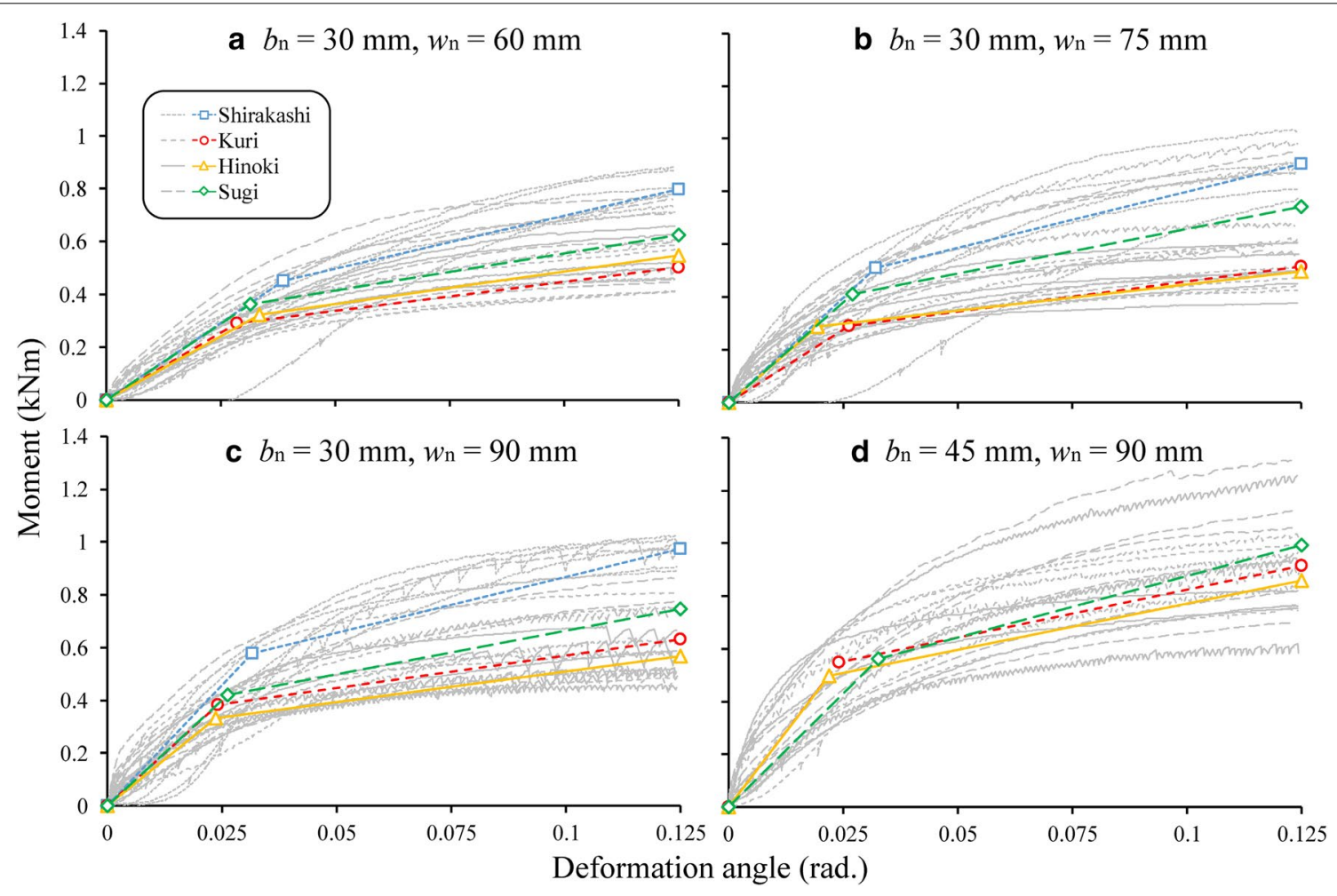

Fig. 3 Relations between moment and deformation angle and bilinear showing the average of characteristic ( $\mathrm{N}$ series) [8]. The closed symbols, in the order of deformation angle, indicate the origin, the average of the coordinate of yield point, and the one of maximum moment. The gray lines show the results for each specimen 
The moment-deformation angle curves were replaced by a perfect elastic-plastic model defined by the standard evaluation method [10]. In the scope of the evaluation, it was assumed that nuki did not pull out horizontally. Further, we calculated the elastic rotational stiffness and the yield moment.

\section{Results and discussion}

\section{Single-piece nuki specimen}

Figure 3 shows the relation between the moment and deformation angle of an $\mathrm{N}$-type nuki-column joint. The experimental values of wood species other than sugi in Fig. 3 use the results of previous study [9]. In Fig. 3, bilinear lines show the averages of the characteristic values for each wood species. Some gray lines have initial slips; they do not pass through the origin, or their initial rising shape is convexly downwards. The reason for this is because there was a gap at the nuki-column joint. Variations in the processing accuracy for each specimen or the drying shrinkage of nuki seem to create these gaps.

Figure 4a shows the typical ultimate state of the N-type specimen. Until the end of the test, no clear failure occurred and the moment continued to increase in all the N-type specimens. Their behavior is characteristic of traditional Japanese timber joints, indicating very large deformability.

Table 1 shows the results of the moment resistance test and the density of the $\mathrm{N}$-type nuki. The results of

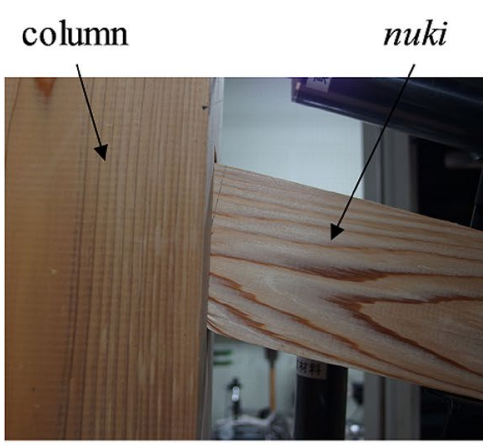

a N-type

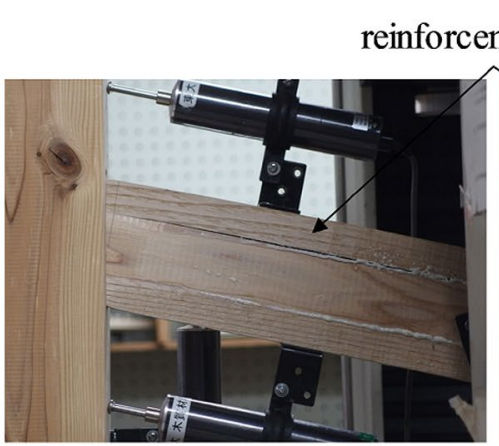

b Rl-type

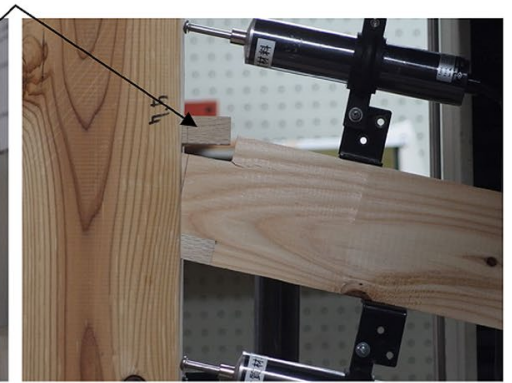

c Rs-type

Fig. 4 Ultimate deformation state

Table 1 Summary of the rotation tests results of $\mathbf{N}$ types

\begin{tabular}{|c|c|c|c|c|c|c|c|c|c|c|}
\hline \multirow[t]{2}{*}{ W.S. } & \multirow[t]{2}{*}{$w_{\mathrm{n}}[\mathrm{mm}]$} & \multirow[t]{2}{*}{$b_{\mathrm{n}}[\mathrm{mm}]$} & \multicolumn{2}{|c|}{$\rho[9]\left[\mathrm{kg} / \mathrm{m}^{3}\right]$} & \multicolumn{2}{|c|}{$M_{\max }[\mathrm{kN} \mathrm{mm}]$} & \multicolumn{2}{|c|}{$M_{\mathrm{y}}[9][\mathrm{kN} \mathrm{mm}]$} & \multicolumn{2}{|c|}{$K$ [9] [k Nm/rad.] } \\
\hline & & & Ave. & $\overline{S D}$ & Ave. & SD & Ave. & SD & Ave. & SD \\
\hline \multirow[t]{3}{*}{ Si } & 30 & 60 & 792 & 25.8 & 799 & 69.6 & 450 & 46.8 & 11.7 & 0.90 \\
\hline & & 75 & 857 & 62.4 & 905 & 99.4 & 508 & 77.4 & 15.8 & 4.19 \\
\hline & & 90 & 848 & 32.6 & 975 & 58.3 & 578 & 24.4 & 18.3 & 2.98 \\
\hline \multirow[t]{4}{*}{ K } & 30 & 60 & 520 & 48.9 & 500 & 97.5 & 291 & 53.5 & 10.2 & 1.72 \\
\hline & & 75 & 493 & 24.1 & 515 & 84.2 & 289 & 48.8 & 11.1 & 2.36 \\
\hline & & 90 & 473 & 55.5 & 633 & 129 & 384 & 62.9 & 15.9 & 5.92 \\
\hline & 45 & 90 & 531 & 41.9 & 917 & 105 & 548 & 85.3 & 22.8 & 7.41 \\
\hline \multirow[t]{4}{*}{$\mathrm{H}$} & 30 & 60 & 469 & 23.6 & 546 & 79.4 & 323 & 42.8 & 9.68 & 0.88 \\
\hline & & 75 & 460 & 30.7 & 497 & 79.7 & 286 & 43.4 & 14.8 & 4.69 \\
\hline & & 90 & 467 & 32.4 & 567 & 83.0 & 333 & 49.7 & 14.1 & 2.43 \\
\hline & 45 & 90 & 482 & 49.9 & 860 & 221 & 499 & 107 & 22.8 & 11.3 \\
\hline \multirow[t]{4}{*}{ Su } & 30 & 60 & 415 & 57.5 & 624 & 148 & 362 & 86.5 & 11.5 & 3.36 \\
\hline & & 75 & 416 & 64.8 & 741 & 183 & 411 & 89.3 & 15.2 & 3.30 \\
\hline & & 90 & 413 & 60.1 & 746 & 170 & 420 & 83.4 & 16.0 & 5.21 \\
\hline & 45 & 90 & 381 & 30.0 & 992 & 223 & 563 & 127 & 17.2 & 4.47 \\
\hline
\end{tabular}

W.S., wood species (Si, K, H and Su represent shirakashi, kuri, hinoki and sugi respectively), $w_{\mathrm{n}}$ : see Fig. $1, b_{\mathrm{n}}$ : see Fig. $1 ; \rho$, density of $n u k i ; M_{\text {max }}$ maximum moment, $M_{\mathrm{y}}$, yield moment; $K$, elastic rotational stiffness; Ave., average; SD, standard deviation 


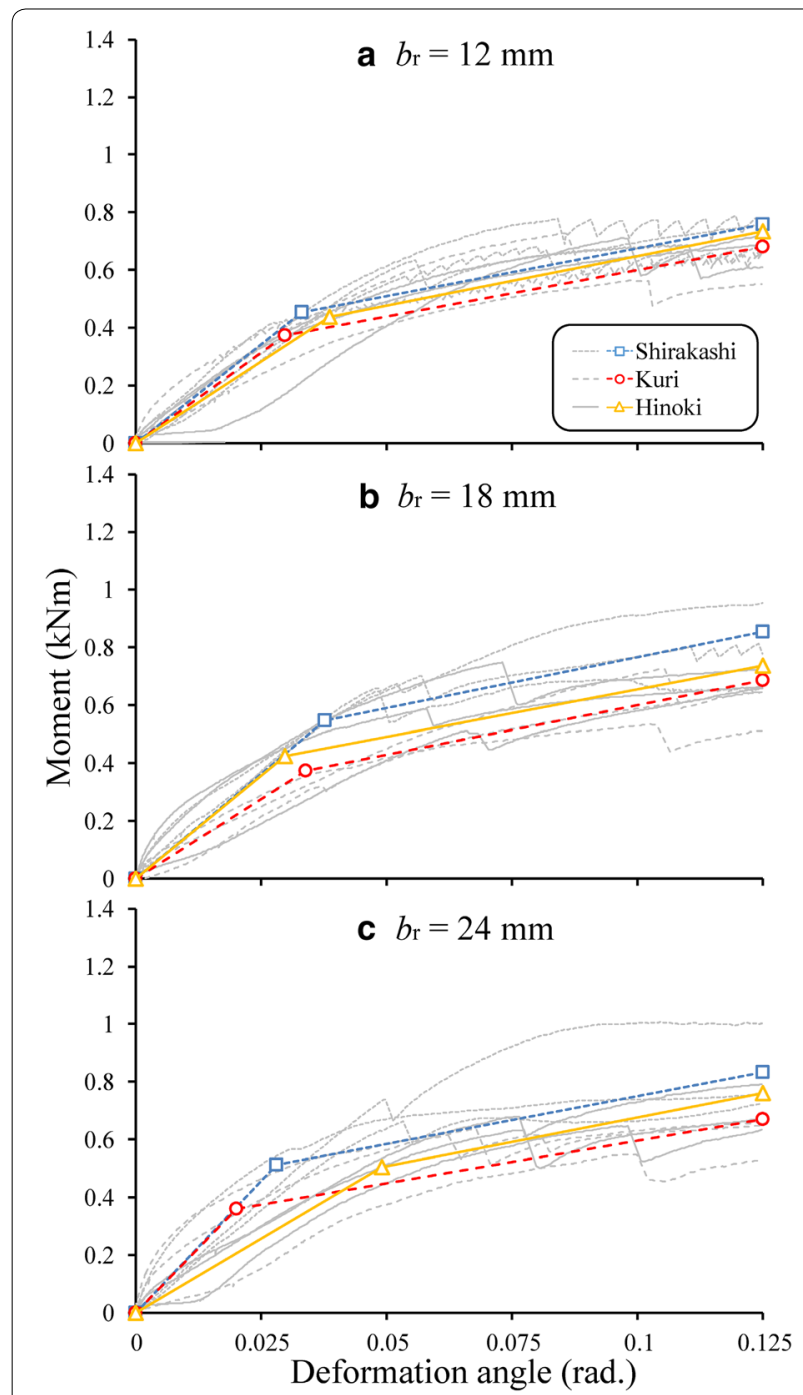

Fig. 5 Relations between moment and deformation angle and bilinear showing the average of characteristic (Rs series) [5]. See Fig. 3

previous reports [9] (i.e., $\rho, M_{\mathrm{y}}, K$ ) are shown in Table 1 in order to compare to the results of sugi. Some results were different from previous reports [9] because we adjusted the initial slips in this study. In Table 1, it generally seems that the elastic rotational stiffness and yield moment are high according to the increasing cross-sectional area.

Except for the result of $w_{\mathrm{n}}=45 \mathrm{~mm}$, the highest values for both the elastic rotational stiffness and yield moment were obtained for the specimen using shirakashi, followed by sugi, kuri, and hinoki. Although the density of sugi was smaller than those of kuri and hinoki, the initial stiffness and yield moment of sugi were larger. Therefore, there may be a more relevant indication of the elastic rotational stiffness than the density when comparing the

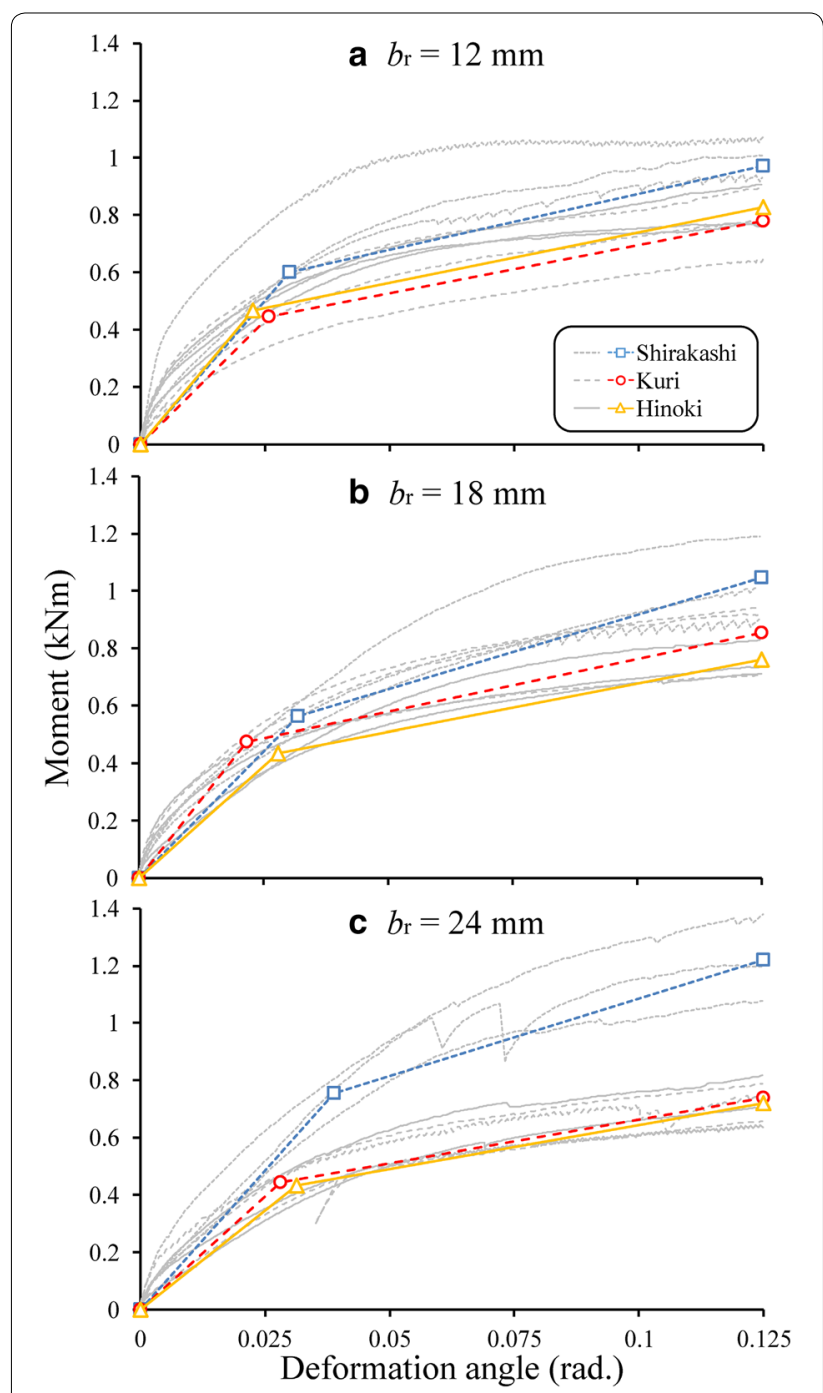

Fig. 6 Relations between moment and deformation angle and bilinear showing the average of characteristic (RI series) [5]. See Fig. 3

characteristic values of nuki-column joints among nuki species. According to the previous research [11-13], gaps in nuki-column joints affect the characteristic values. If we can control or measure the value of the gaps in the nuki-column joints, we may be able to obtain clearer results.

\section{Reinforced nuki specimen}

Figure 5 shows the relations between the moment and deformation angle of the nuki-column joints of Rs and bilinear shows the averages of the characteristic values for each wood species. In 26 out of 27 Rs-type specimens, the reinforcement elements in the upper part of the nuki delaminated (Fig. 4b), and the moment value dropped. Subsequently, cracking from the end of the upper notch 


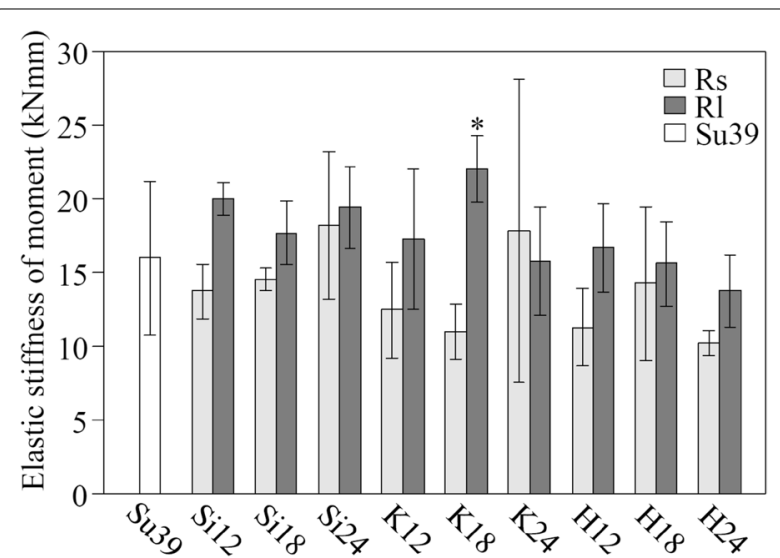

Fig. 7 Averages of the effect of the reinforcement on the elastic stiffness of the moment. The error bar indicates the standard deviation. *: Significant at 5\% level, **: significant at $1 \%$ level. The letters, such as Si12, represent the specimen specifications, as follows: the first letters represent the wood species with $\mathrm{Si}, \mathrm{K}, \mathrm{H}$, and Su representing shirakashi, kuri, hinoki, and sugi, respectively, and the number represents the height of the reinforcement

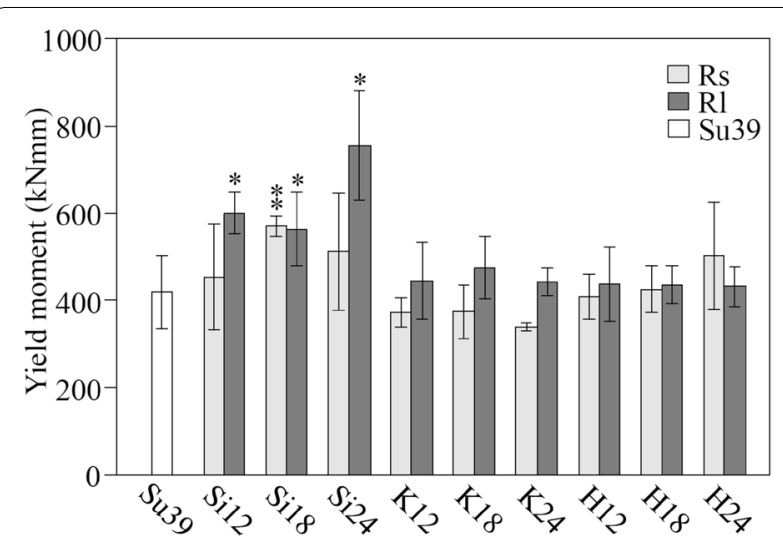

Fig. 8 Averages of reinforcement effect on yield moment. See Fig. 7

of the nuki was observed in 16 specimens. The numbers of the cracked specimens with reinforcements of 12,18 , and $24 \mathrm{~mm}$ in thickness were 1,7 , and 8 , respectively. In almost all the Rs-type specimens, the moment value hardly increased compared to the value obtained when the reinforcement was delaminated (Fig. 4c).

Figure 6 shows the relation between the moment and deformation angle of Rl-type nuki-column joints, and bilinear shows the averages of the characteristic values for each wood species. In 5 out of $27 \mathrm{Rl}$-type specimens, the reinforcements on the upper part of the nuki delaminated. The numbers of the specimens with 18-and 24-mm thick delaminated reinforcements were 1 and 4, respectively. The cause for the differences in the number of specimens with delaminated reinforcements is considered to be the different lengths of the reinforcements.

In the Rs-type system, the butt joints between the reinforcements and nuki were not glued well because only the height of nuki clamped when nuki was cured for. Devising the shape such as scarf joints for gluing well the reinforcements to nuki can possibly prevent the cracks and delaminations. Due to the bending moment generated at nuki, tensile stress was generated at the butt joint between the reinforcements and nuki, and the reinforcement was delaminated. Additionally, stress concentration occurred in the notch of nuki and crack occurred from it. The stress concentration was considered to be increased and crack likely occurred as the thickness of the reinforcement increased. In the Rl-type system, delamination was likely to occur when the thickness of the reinforcement increased. The test results show that if the thickness of the Rl-type reinforcements is below $18 \mathrm{~mm}$, cracks rarely occur.

\section{Effect of reinforcement}

Figure 7 shows the averages and standard deviations of the elastic rotational stiffness of Rs-type, Rl-type, and non-reinforced specimens ( $\mathrm{N}$ type, sugi, $w_{\mathrm{n}}=30 \mathrm{~mm}$, and $b_{\mathrm{n}}=90 \mathrm{~mm}$; Su39). Further, Welch's $t$ test (onesided test) was performed in order to obtain the significant difference between non-reinforced specimens and the specification of Rs-type and Rl-type specimen. As for Fig. 7, the elastic rotational stiffness value of Si12, Si18, Si24, K12, K18, and H12 (Rl types), and Si24 and K18 (Rs types) is higher than that of Su39 by about $4.38-37.5 \%$. (The letters, such as Si12, represent the specimen specifications, as follows: the first letters represent the wood species with $\mathrm{Si}, \mathrm{K}, \mathrm{H}$, and Su representing shirakashi, kuri, hinoki, and sugi, respectively, and the number represents the height of the reinforcement.) There was a significant difference between K18 (Rl type) and Su39 $(p<0.05)$. The average values of the elastic rotational stiffness of the Rl-type system are generally higher than those of the Rs-type system. Because the variations in the values of the elastic rotational stiffness were very large, it was not clarified whether the thickness of the reinforcement affects the characteristic values.

Figure 8 shows the averages and standard deviations of yield moments of the Rs-type, Rl-type, and Su39 systems. Further, significant differences were obtained by Welch's t-test (one-sided test) as in Fig. 7. As for Fig. 8, the yield moment of all of Rl type and Si series, H18, and H24 (Rs-type) are higher than that of Su39 by about $1.20-79.8 \%$. The differences between all of Si (Rl-type) and Si12 and Si18 (Rs-type) and Su39 were significant 
Table 2 Summary of the rotation tests results of Rs and RI types

\begin{tabular}{|c|c|c|c|c|c|c|c|c|c|c|}
\hline \multirow[t]{2}{*}{ Type } & \multirow[t]{2}{*}{ W.S. } & \multirow[t]{2}{*}{$b_{\mathrm{r}}[\mathrm{mm}]$} & \multicolumn{2}{|c|}{$\rho\left[\mathrm{kg} / \mathrm{m}^{3}\right]$} & \multicolumn{2}{|c|}{$M_{\max }[\mathrm{kN} \mathrm{mm}]$} & \multicolumn{2}{|c|}{$M_{\mathrm{y}}[\mathrm{kN} \mathrm{mm}]$} & \multicolumn{2}{|c|}{$K$ [k Nm/rad.] } \\
\hline & & & Ave. & SD & Ave. & SD & Ave. & SD & Ave. & SD \\
\hline \multirow[t]{9}{*}{ Rs } & $\mathrm{Si}$ & 12 & 936 & 32.9 & 741 & 54.8 & 454 & 121 & 13.7 & 1.82 \\
\hline & & 18 & 946 & 17.3 & 816 & 131 & 570 & 23.2 & 14.5 & 0.780 \\
\hline & & 24 & 928 & 21.1 & 827 & 157 & 512 & 134 & 18.2 & 5.00 \\
\hline & K & 12 & 546 & 34.3 & 650 & 82.1 & 372 & 33.8 & 12.5 & 3.23 \\
\hline & & 18 & 543 & 29.6 & 641 & 108 & 374 & 61.6 & 11.0 & 1.86 \\
\hline & & 24 & 551 & 13.8 & 618 & 60.1 & 339 & 8.68 & 17.8 & 10.3 \\
\hline & $\mathrm{H}$ & 12 & 434 & 3.93 & 695 & 15.3 & 408 & 51.9 & 11.3 & 2.62 \\
\hline & & 18 & 425 & 10.4 & 691 & 49.5 & 425 & 53.0 & 14.3 & 5.22 \\
\hline & & 24 & 437 & 14.2 & 743 & 83.5 & 503 & 122 & 10.3 & 0.874 \\
\hline \multirow[t]{9}{*}{$\mathrm{Rl}$} & $\mathrm{Si}$ & 12 & 936 & 32.9 & 974 & 46.4 & 600 & 48.9 & 20.0 & 1.11 \\
\hline & & 18 & 946 & 17.3 & 1034 & 145 & 563 & 84.5 & 17.7 & 2.14 \\
\hline & & 24 & 928 & 21.1 & 1214 & 146 & 755 & 125 & 19.4 & 2.78 \\
\hline & K & 12 & 546 & 34.3 & 778 & 128 & 445 & 89.6 & 17.3 & 4.75 \\
\hline & & 18 & 543 & 29.6 & 853 & 129 & 475 & 72.1 & 22.0 & 2.28 \\
\hline & & 24 & 551 & 13.8 & 729 & 63.3 & 443 & 31.9 & 15.8 & 3.66 \\
\hline & $\mathrm{H}$ & 12 & 434 & 3.93 & 771 & 126 & 438 & 86.1 & 16.7 & 3.02 \\
\hline & & 18 & 425 & 10.4 & 757 & 61.8 & 436 & 42.4 & 15.6 & 2.86 \\
\hline & & 24 & 437 & 14.2 & 720 & 82.3 & 432 & 45.4 & 13.7 & 2.44 \\
\hline
\end{tabular}

W.S., wood species of reinforcements (Si, K, $\mathrm{H}$ and Su represent shirakashi, kuri, hinoki and sugi, respectively), $b_{\mathrm{r}}$ : see Fig. $1 ; \rho$, density of reinforcements; $M_{\max }$ maximum moment; $M_{y}$, yield moment; $K$, elastic rotational stiffness; Ave., average; SD, standard deviation

$(p<0.05)$; in particular, there were significant differences between Si24 (Rl-type) and Su39 $(p<0.01)$. It appears that the yield moment became higher as the thickness of the reinforcement increased. However, the value of the average of the yield moment of Si24 (Rstype) was lower than that of Si18 (Rs-type), and the value of the standard deviation of the yield moment of Si24 (Rs-type) was higher than that of Si18.

Table 2 shows the results of the moment test and the reinforcement-element density for the Rs- and Rl-type systems. In Table 2, densities are the average of the density of two reinforcements in one reinforced nuki. Comparing the density of the reinforcement, Si24 exhibits a larger standard deviation and a smaller average than Si18. This seems to be one of the reasons why the variation of the yield moment of Si24 (Rs-type) increased. We cannot provide the exact reason; however, it appears that variations in the density of the reinforcements have a larger impact on the yield moment than the differences among specifications. Therefore, if we control the density of the reinforcement, the deviations in the yield moment may decrease and it may be possible to obtain the quantitative results. Additionally, if the density is related to the yield moment, you may be able to control the yield moment by managing the density. These results show that by utilizing shirakashi as Rl-type reinforcements, the yield moment and elastic rotational stiffness of nuki-column joints can be improved. Moreover, it appears that if you use shirakashi as Rs-type reinforcement in nuki-column joints, the yield moment of the nuki-column joints can be increased.

\section{Conclusion}

To improve the characteristic values of nuki-column joints with low elastic stiffness of the moment, experiments on joints reinforced using hardwood were performed. In Rl type, the test results clarified that the moment resistance performances of nuki-column joints, such as the elastic rotational stiffness and the yield moment, were improved by utilizing hardwoods at the joint. In particular, utilizing shirakashi as reinforcements seems to be significantly effective on yield moments. There were more Rs-type specimens that the reinforcements delaminated from than Rl-type specimens. In Rs type, yield moment of the joint was improved by using shirakashi at the joint. The differences in deformation behavior between Rs-type and Rl-type specimens seem to cause by the shape of the reinforcements. The shape of 
the reinforcements has room for further study. The yield moment of nuki-column joints with hardwood reinforcements seems to be related to the density of the reinforcements. Therefore, it was suggested that the yield moment of the nuki-column joint can be controlled by the density of the reinforcements to some extent. On the other hand, it seems that the density of the reinforcements does not affect the elastic rotational stiffness of nuki-column joints with hardwood reinforcements. It is necessary to find other factors (e.g., gaps in the joints) that affect the characteristic value rather than the reinforcements' density in order to control the performance improvement effect by this method more precisely.

However, in order to use this reinforcing system for practical applications, quantitative evaluation of the reinforcing effect is needed. Thus, it is necessary to clarify the relationship between the density and the Young's modulus perpendicular to the grain of the reinforcements considering anatomical features, such as annual ling angle.

\section{Abbreviations}

Su39: non-reinforced specimens ( $\mathrm{N}$ type, sugi, $w_{\mathrm{n}}=30 \mathrm{~mm}$, and $b_{\mathrm{n}}=90$ $\mathrm{mm})$; Su: sugi (Cryptomeria japonica); Si: shirakashi (Quercus myrsinifolia); K: kuri (Castanea crenata); H: hinoki (Chamaecyparis obtusa).

\section{Acknowledgements} Nothing.

Part of this report was presented at the 66th Annual Meeting of the Japan Wood Research Society, Tokyo, March 2015, the 67th Annual Meeting of the Japan Wood Research Society, Nagoya, March 2016, and the 15th World Conference on Timber Engineering, Seoul, Republic of Korea, August 2018.

\section{Authors' contributions}

$\mathrm{HS}, \mathrm{KA}$, and $\mathrm{MI}$ designed the experiments. HS performed the experiments, analyzed the data, and was a major contributor in writing the manuscript. All authors contributed to interpretation and discussed results. All authors read and approved the final manuscript.

\section{Funding}

Part of this work was supported by The Ministry of Land, Infrastructure, Transport and Tourism "2014 Building Standards Improvement Promotion Project."

\section{Availability of data and materials}

The datasets used and analyzed in the current study are available from the corresponding author on reasonable request.

\section{Competing interests}

The authors declare that they have no competing interests.

\section{Author details}

${ }^{1}$ Forestry and Forest Products Research Institute, 1 Matsunosato, Tsukuba, Ibaraki 305-8687, Japan. ${ }^{2}$ Graduate School of Agriculture and Life Science, The University of Tokyo, 1-1-1 Yayoi, Bunkyo-ku, Tokyo 113-9657, Japan.
Received: 26 July 2019 Accepted: 25 November 2019

Published online: 04 December 2019

\section{References}

1. Ministry of Agriculture, Forestry and Fisheries (2019) Outline of yearbook of Timber Statistics in 2018. http://www.maff.go.jp/j/tokei/kouhyou/ mokuzai/index.html\#y. Accessed 25 July 2019

2. Fujita K, Inayama M, Ando N (2012) Embedding performance of four kinds of domestic hard wood used as wooden dowels (in Japanese). Mokuzai Gakkaishi 58(4):181-192

3. Yamai R (1959) Studies on the characteristic properties of wood in partial compression. 1. On the distribution of strains in direction of loading (1) (in Japanese). Mokuzai Gakkaishi 5(5):189-193

4. Kitamori A, Kato Y, Kataoka Y, Komatsu K (2003) Proposal for a mechanical model of beam-column "nuki" joints in traditional timber structures (in Japanese). Mokuzai Gakkaishi 49(3):179-186

5. Fujita K, Kobayashi Y, Kawahara H, Inayama M, Gotou M, Takahashi K (2011) Moment resisting performance of Japanese traditional wooden joints feature of each joint and presumption of moment resisting performance in crosstype joiont (in Japanese). J Struct Constr Eng 76(665):1299-1308

6. Nakajima S, Kitamori A, Komatsu K (2011) Reinforcement of tensile bolted moment resisting joint by hardwood bearing plate (in Japanese). In: Abstracts of the 61st annual meeting of the Japan Wood Research Society, Kyoto, Japan, 18-20 March, H20-04-0915

7. Gotoh K (1986) Research on the wooden semi-rigid frame (nuki-structure) No.1. J Struct Constr Eng 410:19-25

8. Wanninger F, Frangi A (2014) Experimental analysis of a post-tensioned timber connection. In: Aicher S, Reinhardt H-W, Garrecht H (eds) Materials and joints in timber structures. RILEM Bookseries, vol 9. Springer, Netherlands

9. Suesada H, Inayama M, Souma T, Aoki K (2017) Performance of rotational moment resistance of column and nuki joint using hardwood (in Japanese). Wood Ind 72(6):220-225

10. Japan Housing and Wood Technology Center (2008) Allowable stress design for wooden post and beam construction houses (in Japanese). Japan Housing and Wood Technology Center, Tokyo

11. Ogawa K, Sasaki Y, Yamasaki M (2016) Theoretical estimation of the mechanical performance of traditional mortise-tenon joint involving a gap. J Wood Sci 62:242-250

12. Chang WS, Hsu MF, Komatsu K (2006) Rotational performance of traditional Nuki joints with gap I: theory and verification. J Wood Sci 52:58-62

13. Chang WS, Hsu MF (2007) Rotational performance of traditional Nuki joints with gap II: the behavior of butted Nuki joint and its comparison with continuous Nuki joint. J Wood Sci 53:401-407

\section{Publisher's Note}

Springer Nature remains neutral with regard to jurisdictional claims in published maps and institutional affiliations.

\section{Submit your manuscript to a SpringerOpen ${ }^{\odot}$ journal and benefit from:}

- Convenient online submission

- Rigorous peer review

- Open access: articles freely available online

- High visibility within the field

- Retaining the copyright to your article

Submit your next manuscript at springeropen.com 